Supplement of Atmos. Chem. Phys., 15, 6503-6519, 2015

http://www.atmos-chem-phys.net/15/6503/2015/

doi:10.5194/acp-15-6503-2015-supplement

(C) Author(s) 2015. CC Attribution 3.0 License.

(c) (i)

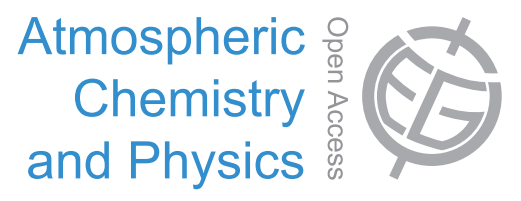

Supplement of

\title{
Particulate emissions from residential wood combustion in Europe - re- vised estimates and an evaluation
}

H. A. C. Denier van der Gon et al.

Correspondence to: H. A. C. Denier van der Gon (hugo.deniervandergon@tno.nl)

The copyright of individual parts of the supplement might differ from the CC-BY 3.0 licence. 
Table S1. Point sources and area sources distinguished in the gridding of the emissions.

\begin{tabular}{|c|c|}
\hline Point sources & Area sources \\
\hline 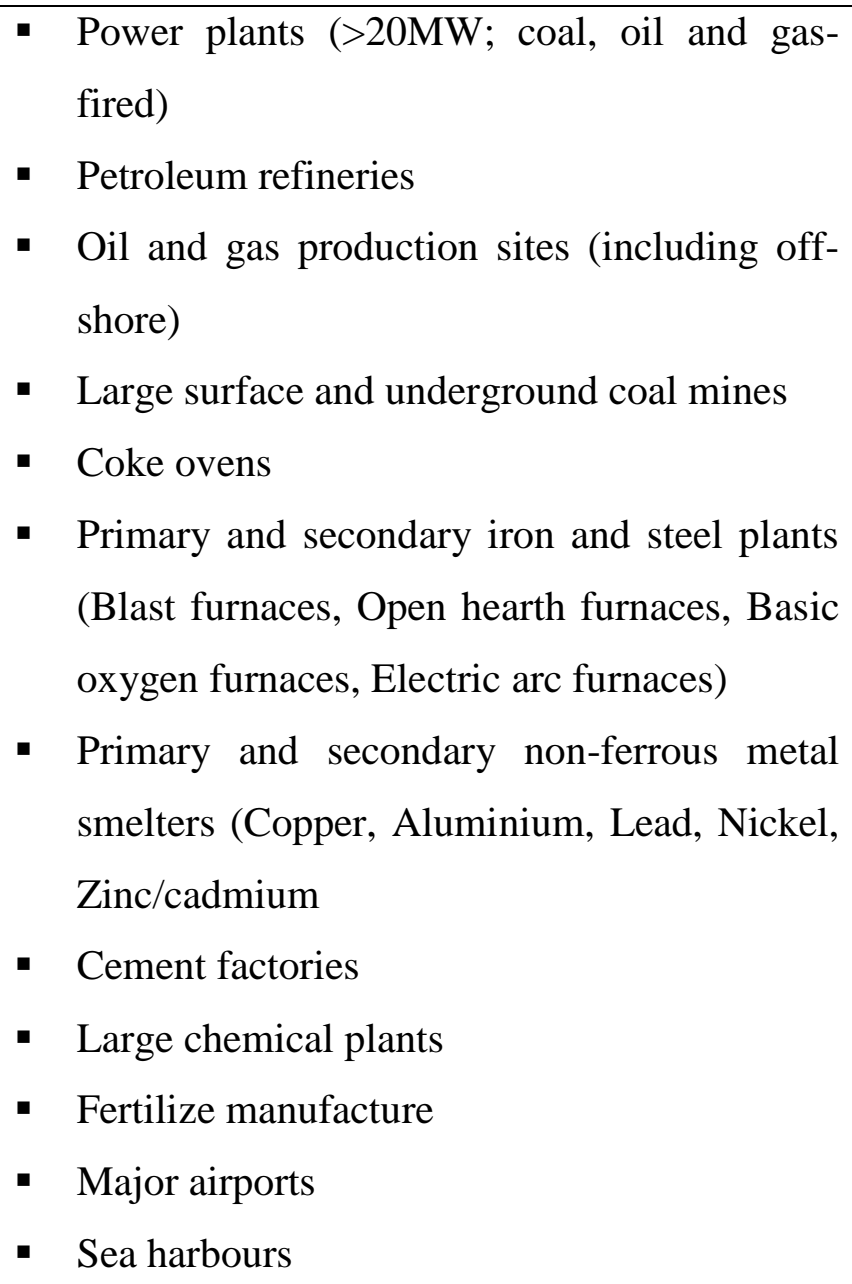 & $\begin{array}{l}\text { - Population, split into an urban and } \\
\text { a rural part } \\
\text { - Land cover and land use, including } \\
\text { arable land } \\
\text { - Road maps (location and traffic } \\
\text { intensity) of larger roads } \\
\text { - Rail network } \\
\text { - Inland waterways } \\
\text { - Sea shipping routes and intensities } \\
\text { - Farm animal populations (pigs, } \\
\text { poultry, cattle, sheep \& goats, } \\
\text { horses) } \\
\text { - A specific map for residential } \\
\text { wood combustion (see section 2.3) }\end{array}$ \\
\hline
\end{tabular}


Table S2. Types of devices usage assumed for specific countries.

\begin{tabular}{|l|c|c|}
\hline & $\begin{array}{c}\text { Central and } \\
\text { Eastern Europe }\end{array}$ & $\begin{array}{c}\text { Former } \\
\text { Yugoslavia }\end{array}$ \\
\hline Fire place & $5 \%$ & $5 \%$ \\
\hline Traditional heating stove & $83 \%$ & $55 \%$ \\
\hline Single house boiler manual & $2 \%$ & $20 \%$ \\
\hline Single house boiler automatic & $0 \%$ & $5 \%$ \\
\hline Medium boiler manual & $10 \%$ & $5 \%$ \\
\hline Medium boiler automatic & $1 \%$ & $10 \%$ \\
\hline
\end{tabular}


Table S3. Evaluation of EMEP MSC-W model prediction results (with two different inventories for residential wood combustion emissions) to data from available observations in 2007-2009 (all seasons). $\mathrm{N}=$ number of measurements, Obsvd = Average Measured OC concentration, Model $=$ Average modelled OC concentration (for the periods with measurements), $\mathrm{R}^{2}=$ coefficient of determination, $\mathrm{MAE}=$ Mean of Absolute Error. Unit for Obsvd, Model and MAE: $\mu \mathrm{g}(\mathrm{C}) \mathrm{m}^{-3}$. The relative MAE $=$ MAE/Obsvd (in \%, within brackets).

\begin{tabular}{|c|c|c|c|c|c|c|c|c|}
\hline & & \multicolumn{4}{|c|}{ EUCAARI emissions } & \multicolumn{3}{|c|}{ TNO revised RWC emissions } \\
\hline Site & $\mathrm{N}$ & Obsvd & Model & $\mathrm{R}^{2}$ & MAE & Model & $\mathrm{R}^{2}$ & MAE \\
\hline 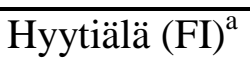 & 248 & 1.06 & 0.86 & 0.54 & $0.36(34 \%)$ & 1.13 & 0.62 & $0.39(37 \%)$ \\
\hline $\begin{array}{l}\text { Aspvreten } \\
(\mathrm{SE})^{\mathrm{b}}\end{array}$ & 277 & 1.75 & 1.01 & 0.37 & $0.82(47 \%)$ & 1.24 & 0.44 & $0.70(40 \%)$ \\
\hline Vavihill $(\mathrm{SE})^{\mathrm{c}}$ & 73 & 1.55 & 1.00 & 0.25 & $0.63(41 \%)$ & 1.20 & 0.38 & $0.50(32 \%)$ \\
\hline Melpitz (DE) ${ }^{\mathrm{d}}$ & 1051 & 1.81 & 1.18 & 0.25 & $0.91(50 \%)$ & 1.58 & 0.41 & $0.75(42 \%)$ \\
\hline $\begin{array}{l}\text { Overtoom } \\
(\mathrm{NL})^{\mathrm{e}}\end{array}$ & 140 & 2.12 & 1.05 & 0.44 & $1.16(55 \%)$ & 1.34 & 0.60 & $0.95(45 \%)$ \\
\hline $\begin{array}{l}\text { Birkenes } \\
(\mathrm{NO})^{\mathrm{f}}\end{array}$ & 265 & 0.68 & 0.73 & 0.57 & $0.29(43 \%)$ & 0.72 & 0.58 & $0.30(44 \%)$ \\
\hline
\end{tabular}

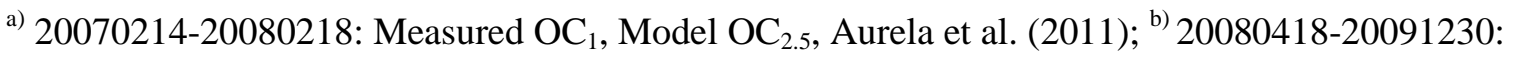
$\mathrm{OC}_{10} ;{ }^{\mathrm{c})}$ 20080424-20091231: OC 10 , Genberg et al. (2011); ${ }^{\mathrm{d})}$ 20070101-20091231: $\mathrm{OC}_{2.5}$, ${ }^{\mathrm{e}}$ Note: Urban background station, Amsterdam (the station is not heavily influenced by RWC and OC concentrations are similar to surrounding rural background sites, Schaap and Denier van der Gon, 2007), 20070218-20081231: OC $_{2.5}{ }^{\text {f) }}$ 20070102-20091229: OC $_{2.5}$. 

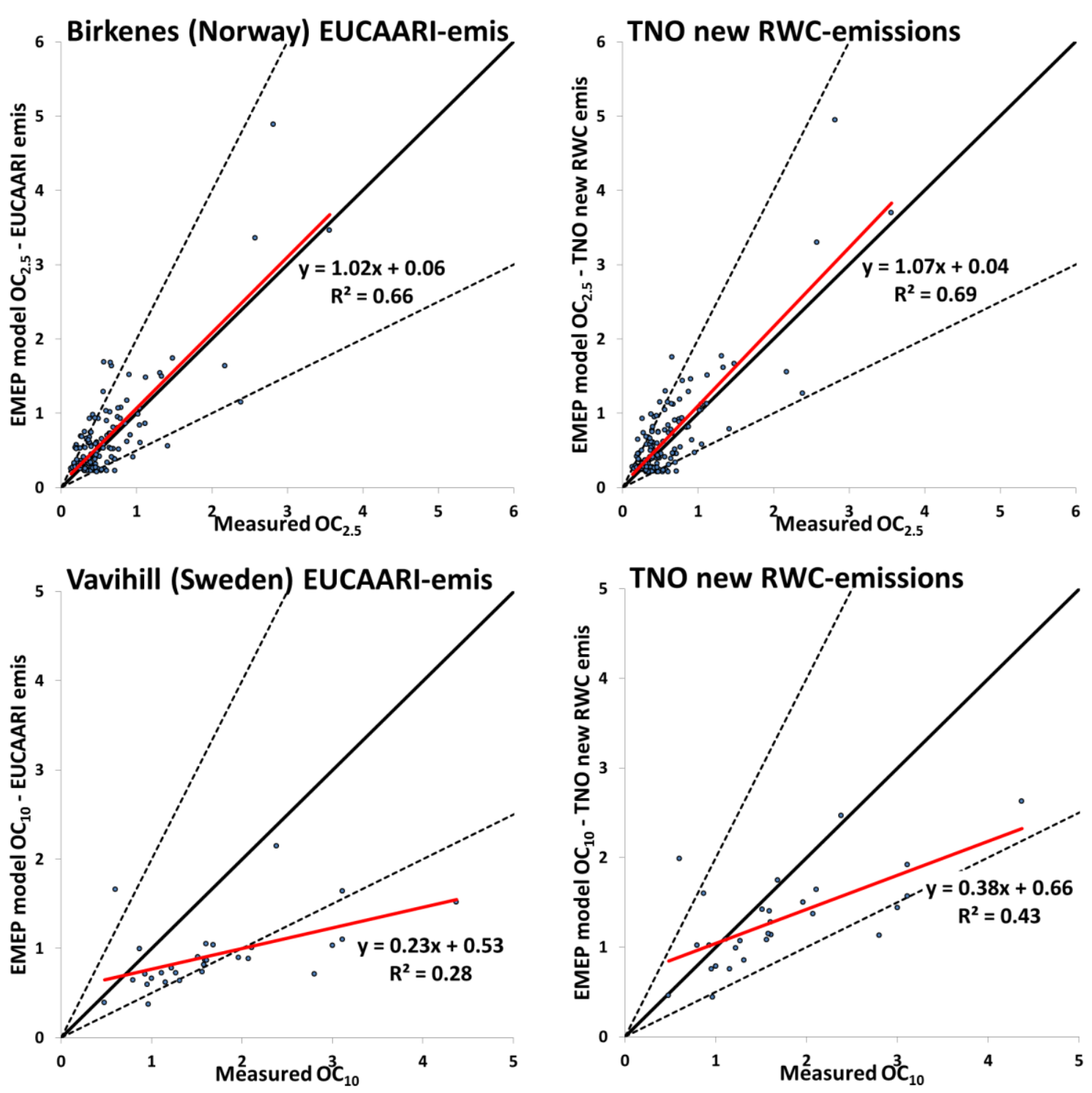

Figure S1. Measured and modelled OC concentrations at Birkenes (Norway) and Vavihill (Sweden) during winter half-year periods (November-April). The left-side plots show EMEP MSC-W model results using the EUCAARI emissions and the right-side plots results using the revised residential wood combustion emissions. For Birkenes OC in $\mathrm{PM}_{2.5}$ is shown and for Vavihill OC in $\mathrm{PM}_{10}$. Unit: $\mu \mathrm{g}(\mathrm{C}) \mathrm{m}^{-3}$. Further details see Table 4 . 


\section{The boundary layer height and residential wood combustion emissions}

It is difficult to model the boundary layer height accurately in large scale chemical transport models and there is a risk that the models will underestimate PM from residential wood combustion (RWC), and other local, low stack-height sources, during calm, cold nights with strong temperature inversions. If the model overestimates the mixing height during these conditions (which is very likely) the PM concentrations due to local RWC will be underestimated close to the source.

However, the turbulence parameterization and calculation of the atmospheric boundary layer (ABL) height in the EMEP MSC-W model were updated a few years ago (Jeričević et al., 2010) and evaluation against radiosound data, and data from the Cabauw tower, showed that the EMEP model is able to reproduce spatial and temporal mixing height variability fairly well.

Since measurements of the ABL are usually not available for the same sites (and time periods) as the PM concentrations we can not directly compare the model bias for PM in the present study to observed ABL. Instead we have compared the model bias for $\mathrm{OC}$ to the modelled mixing height $\left(\mathrm{H}_{\text {mix }}\right)$ and air temperature at $2 \mathrm{~m}$ height $\left(\mathrm{T}_{2 \mathrm{~m}}\right)$. This may give some indication if there are general problems with under or overestimation in the model during cold and stable conditions.

The correlation between the model bias (for $\mathrm{OC}$ ) and $\mathrm{H}_{\text {mix }}$ or $\mathrm{T}_{2 \mathrm{~m}}$ varies between the six different sites included in the 2007-2009 evaluation of the EMEP MSC-W model. When looking at all (winter-half year) data, from all six sites, (Fig. S2), there is a tendency that the model underestimates OC for periods with low model $\mathrm{H}_{\text {mix }}$, when using the old emission inventory for RWC (but the correlation between OC-bias and $\mathrm{H}_{\text {mix }}$ is fairly low, $\mathrm{R}^{2}=0.084$ ). When using the revised RWC emission inventory (TNO-newRWC) the underestimation at low modelled $\mathrm{H}_{\text {mix }}$ decrease markedly and the correlation between the OC-bias and $\mathrm{H}_{\text {mix }}$ drops to a very low value $\left(\mathrm{R}^{2}=0.017\right.$, see Fig. $\left.\mathrm{S} 3\right)$.

The correlation between the model bias for OC and near surface temperatures is close to zero, both with the old and with the revised RWC emission inventory (see Fig. S4 and S5). So, at least for total OC, the EMEP MSC-W model does not seem to produce significantly worse results at low temperature periods than during milder conditions. Since OC is by far the dominant component in PM from RWC, this conclusion holds for $\mathrm{PM}_{2.5}$ or $\mathrm{PM}_{10}$ as well.

Reference: Jeričević, A., Kraljević, L., Grisogono, B., Fagerli, H., and Večenaj, Ž.: Parameterization of vertical diffusion and the atmospheric boundary layer height determination in the EMEP model, Atmos. Chem. Phys., 10, 341-364, doi:10.5194/acp-10-341-2010, 2010. 


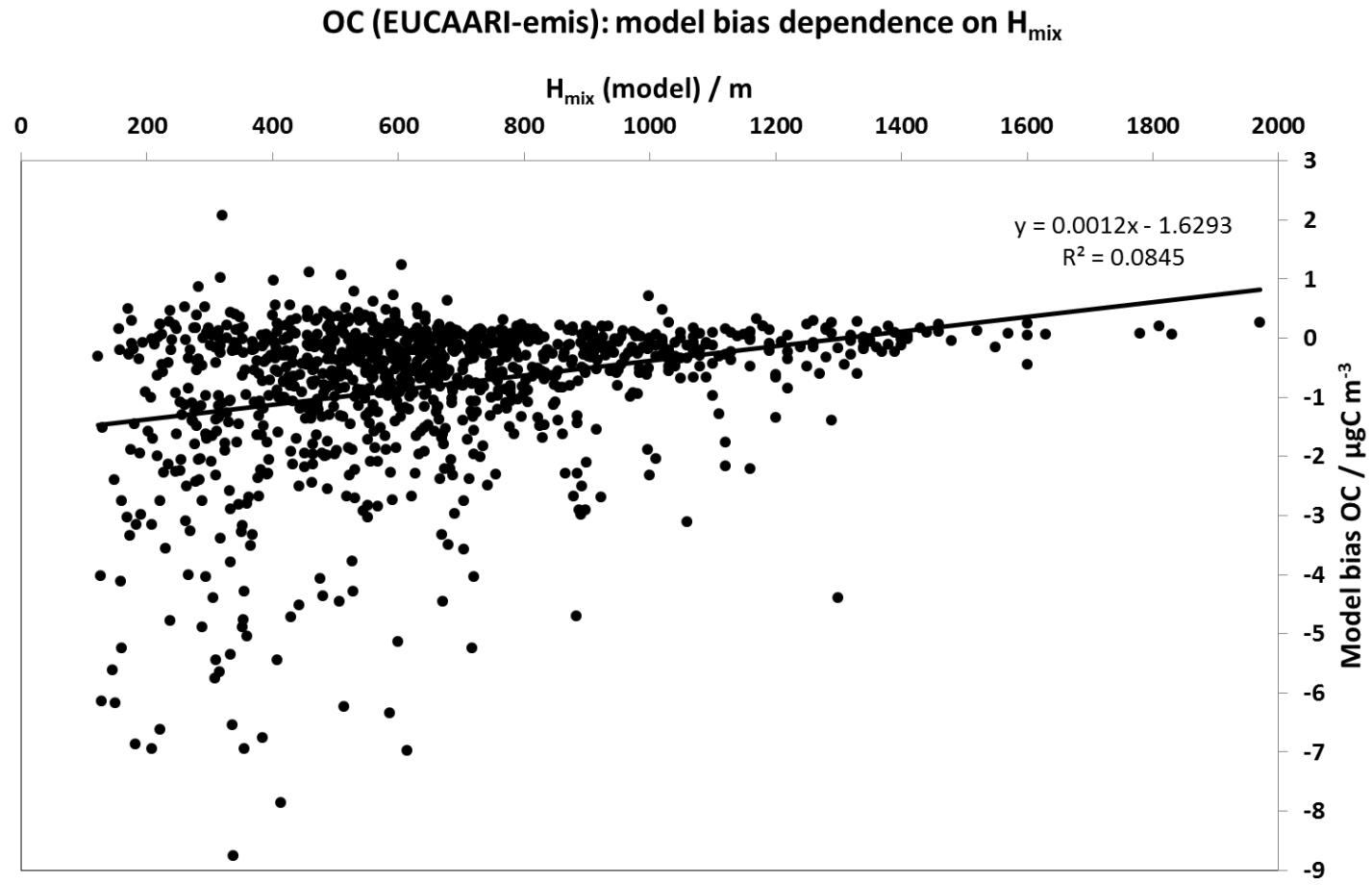

Figure S2. Scatter plot of model bias for particulate organic carbon (OC) concentrations with the old (EUCAARI) emission inventory for residential combustion [model OC - measured OC] and modelled boundary layer height $\left(\mathrm{H}_{\text {mix }}\right)$ using winter half-year (Nov-Apr) data from 2007-2009 from the six stations Hyytiälä, Aspvreten, Vavihill, Melpitz, Overtoom and Birkenes (see manuscript for further details).

OC (TNO-newRWC-emis): model bias dependence on $\mathrm{H}_{\text {mix }}$

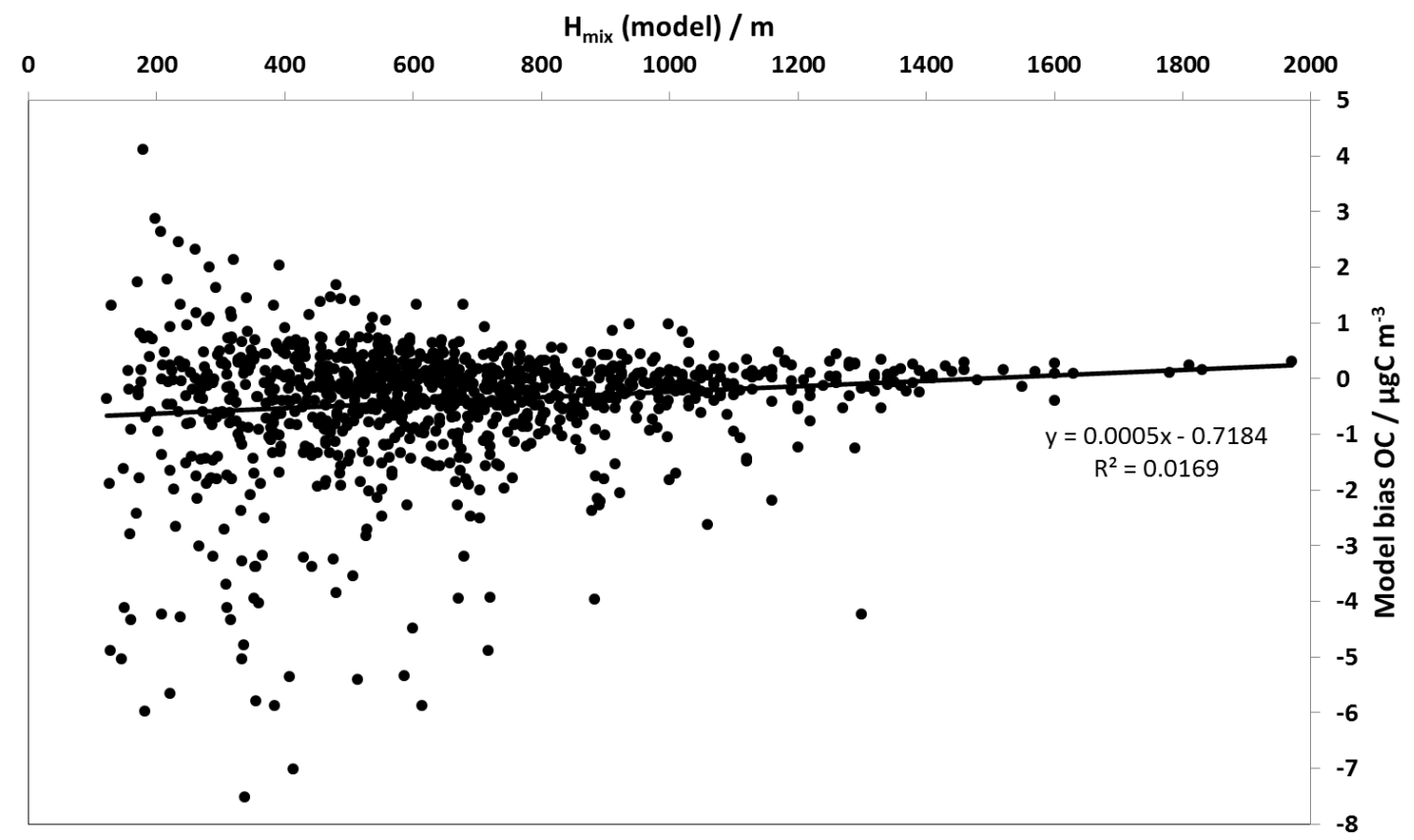

Figure S3. As Fig. S2 but model OC bias based on simulation with the revised (TNO-new RWC) emission inventory. 
OC (EUCAARI-emis): model bias dependence on $\mathrm{T}_{2 \mathrm{~m}}$

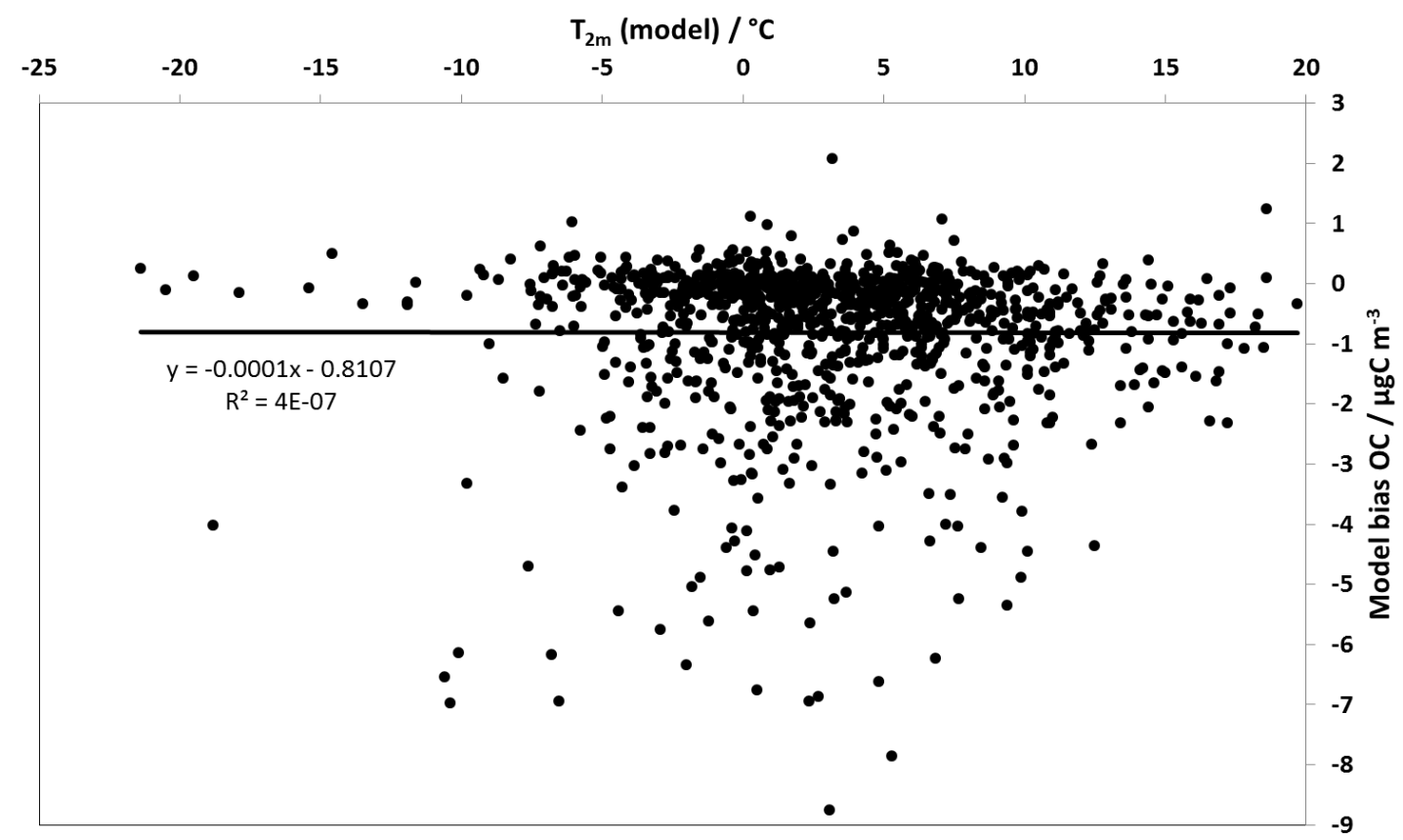

Figure S4. As Fig. S2 but plotting model OC bias against modelled $2 \mathrm{~m}$-temperature $\left(\mathrm{T}_{2 \mathrm{~m}}\right)$.

OC (TNO-newRWC-emis): model bias dependence on $T_{2 m}$

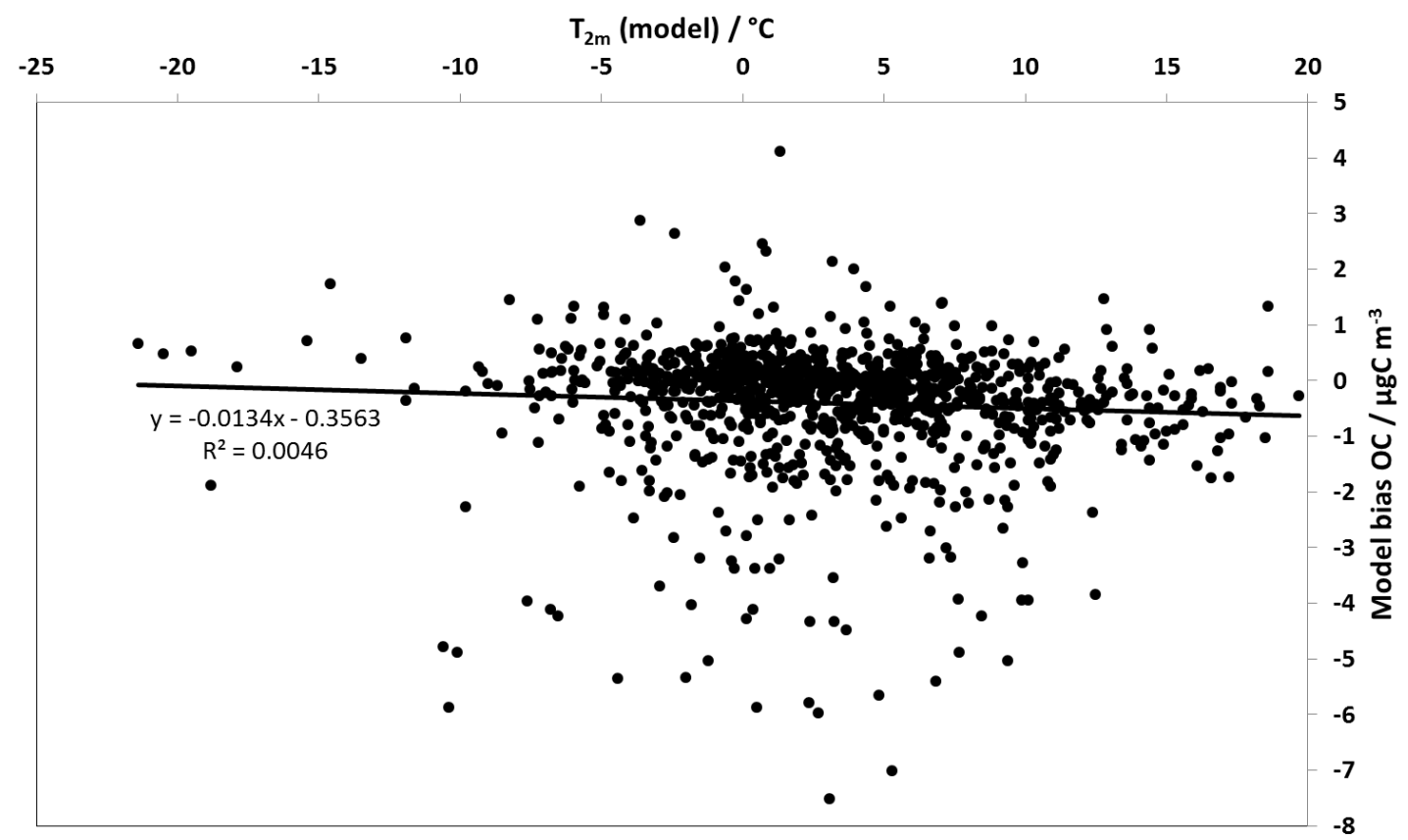

Figure S5. As Fig. S4 but model OC bias based on simulation with the revised (TNO-new RWC) emission inventory. 